\title{
3D Experiences - Dassault Systèmes 3DS Strategy to Support New Processes in Product Development and Early Customer Involvement
}

\author{
Andreas Barth \\ VP and Managing Director, Dassault Systèmes Deutschland GmbH \\ andreas.barth@3ds.com
}

\begin{abstract}
In many industries the market sees a lot of change happening these days; new trends and challenges obviously need to be addressed as part of the product creation process. Dassault Systèmes (3DS) is introducing a 3DEXPERIENCE PLATFORM to expand the usability of the digital smart product development in an accurate virtual universe beyond Product Lifecycle Management (PLM). The target is to provide the ability to place the customer at the heart of a system, integrating both company business processes and product development processes. It is a combination of science, art and technology to bring value to our customers by helping them to respond to the needs of their customers and creating 'magnetic' products with strong market appeals. 3DExperiences can be a catalyst for innovation, enabling any enterprise stakeholder to participate in the innovation process, contributing to drive value for the end consumer and create smart products from design to recycling. This presentation highlights some aspects of the new Dassault Systèmes strategy; shows some of the solution experiences and how customers respond to them. 3DS is a scientific company positioned among the top 10 software companies worldwide and for more than 30 years has been helping companies to transform the way they design and produce their products.
\end{abstract}

Keywords: 3DExperience, CATIA, Innovation, DMU, Smart Product.

\section{Introduction}

Innovation is driven by change and the consumer markets do change rapidly these days. Mobility requirements for instance do have strong impacts on the TeleCommunication Industry (mobile devices such as smartphones, tablets ...) and on the Transportation \& Mobility Industry (Electro mobility, personal mobility, sustainability ...). It's the first time in industrial history that innovation is more driven by end consumer needs rather than by engineering and manufacturing companies.

\section{$2 \quad$ Why Is Change Necessary?}

It is a complex challenge to move from traditional engineering to Smart Product development. Forward-thinking executives are, quite rightly, demanding more and 
better consumer insight and smarter research to measure impacts of potential new innovations. Companies can gain an understanding of their customers which is better, faster, and less expensive by doing four things called the "digital research revolution":

1. Leverage the digital society power to rapidly create and deliver detailed information about what would be products customer acceptance information.

2. Recognize the limitations of the measurement systems based on projected past or isolated focus groups.

3. Seek to understand what customers value the most and how technologies and innovation can deliver and enhance the product value.

4. Link investigations into consumer insights based on virtual product candidates that are sorting value very close to their customer relationships management systems and create criteria such as "Cool Feature", "Must Have", etc.

\subsection{Leverage the Power of the Digital Society}

The Internet is fast. It enables any type of digital exchange and can leverage data in many forms plus has the ability to create many more iterations with a turnaround in a few days, rather than weeks required for traditional methods. Marketing strategy segmentations for innovation that used to take months can be completed in weeks. Working digitally is also less expensive than prototyping/ face-to-face studies and can be conducted with dramatically larger sample sizes. Finally, customers' online comments, search behavior, and other revelations offer a prove of data.

\subsection{Decrease Reliance on Traditional Prototypes and Focus Groups}

Focus groups were once the default qualitative research approach. Companies gathered small numbers of consumers in a facility around real prototypes for some hours, promised them a small payment or free products, and asked them to give simple written or oral answers to questions that may or may not have provided real insight. Despite the emergence of better alternatives, little has changed yet.

Full usage of Virtual Product candidates now enables leading marketers to create deep immersion experiences with a large number of users organized through communities to generate consumer insights and new products; consider values and positioning; and redefine a product's competitive set. These ideas can then be tested quantitatively, either through further research or a market pilot.

\subsection{Understand How Successful Products Are Created}

Companies have long focused on what and why people buy. Research data from consulting companies like Oliver Wyman show that this is not sufficient.

They clearly show that only few high-quality products are magnetic ${ }^{1}$, defining "magnetic" by a simple equation: $\mathrm{M}=\mathrm{F} \times \mathrm{E}$. Magnetic equals best functionality times

\footnotetext{
${ }^{1}$ Magnetic $=$ having a great power of attraction over people.
} 
most powerful emotional connection with customers. Very good functionality is obviously not enough anymore.

\subsection{Connect What You Know about Consumer Value}

Why do consumers disproportionately demand one product over a seemingly similar one, often by a factor of four or five to one? Functionally and technically, products might be close; emotionally, they can be worlds apart. Why do seemingly similar products produce radically different demand curves?

Demand creators, people who design products that truly excite consumers, are obsessed with understanding customer values, and connecting the dots from multiple value chains to fix it. They don't assume that buying = wanting. They use the value map to recognize the huge gaps between what people buy and what they really value including emotionally - and use those value map as a springboard to see differently. Demand creators crack the mystery of the demand equation by doing a radically better job answering a small set of critical value and differentiation questions very well.

\section{The Concept of 3dexperiences By Dassault Systèmes}

How can a Software tool vendor support demand creators?

3DS has initialized a large change to apply the power of the Digital Society to help product creators with the new challenges described above: Introduce the ability to create Smart Products from an unified digital representation that are all interacting together to create a "Virtual" Smart Product.

To reach customers but also to ensure that fast development cycles based on value of a product that can actually be produced can be achieved digitally, a "Virtual" Smart Product needs to be digitally accurate. This product accuracy is not sufficient to help creators if it is not also possible to benefit from similar accuracy in the digital modeling of the environment in which the products will be used.

And of course measuring value and making product creators able to deliver the magnetic products described above means that ability to interface with large communities and finally partners including suppliers, channels and consumers are requesting interacting socially in fast and efficient digital loops.

3DS has started to create a Product Creator Digital Platform that has the ambition to complete the digital landscape compared to other platform technologies

- Facebook as a social platform

- Wikipedia as a knowledge platform

- Android as a development platform
Google as a search platform

App stores as a services and applications platform

YouTube, iTunes and others as a content platform 


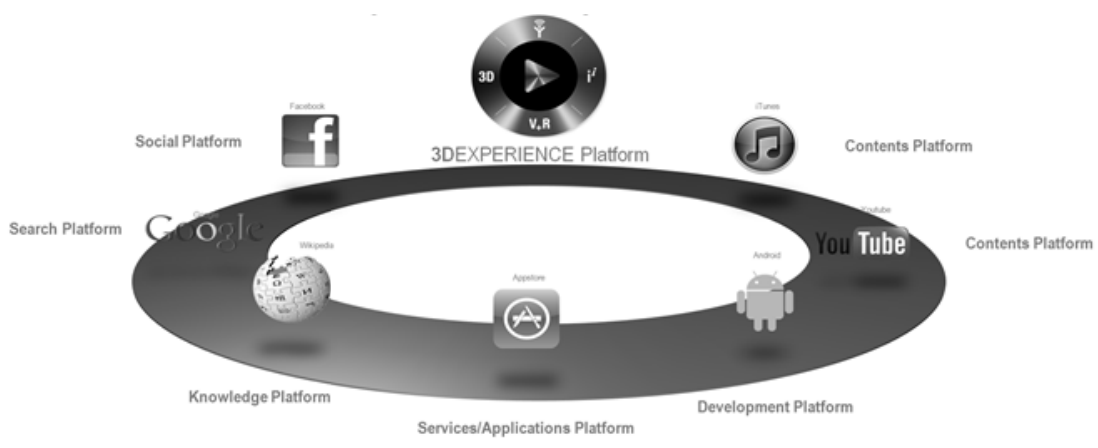

Fig. 1. 3DExperience Platform compared to other platform technologies

This Product Creator Digital Platform is named 3DExperience platform and is designed to socially link the large communities of contributors in product developments required to create Smart Products.

The integration is done around real accurate Digital Virtual Smart Products that are leveraging the 3DS $20+$ years of experience in creating accurate engineering around 3D based digital engineering.

The target is to provide the same accuracy that was obtained on geometry to the other engineering domains. The target is not to provide game platforms but to enable the magnetic product creation to be done socially based on the real physics and manufacturability of the products - this can be seen as a natural extension to the Product Lifecycle Management market (PLM).

The representation of this strategy is indicated by a user interface to access the software and data platform in the form of a compass as a synonym for a highly integrated application environment and a platform concept.

\section{User Experiences By Industry}

The 3DS new 3DExperience platform is to be delivered for 12 industries - that produce Smart Products including the more traditional customers of the company such as Automotive, Aerospace and Industrial Equipment to new customers such as high volume Consumer Packaged Goods, Retail, Energy, Process and Utilities, Financial and Business Services, Life Science and more.
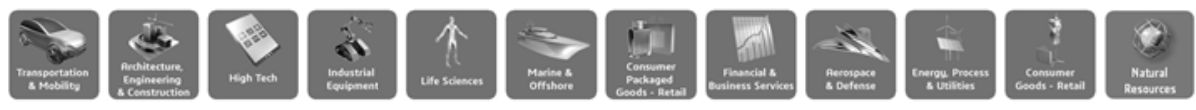

Fig. 2. Dassault Systèmes supports 12 Industries 
A. Barth

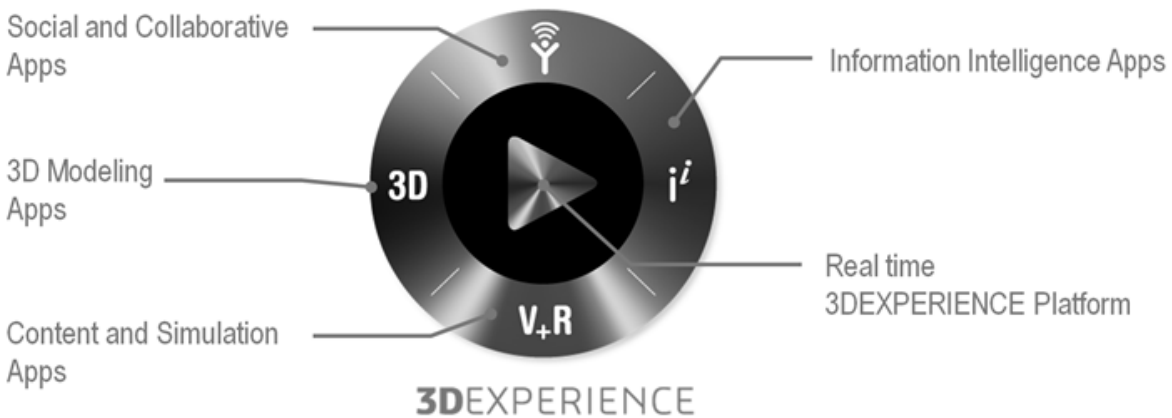

Fig. 3. 3DExperience Platform Compass

\subsection{PLM Innovation By Engineered Business Experience}

Overall the changes, whether it is the market, the consumer buying behavior, new products, changed mobility etc. have a significant impact on the way engineering will work in the future.

$\begin{array}{llll}\text { From } & \begin{array}{c}\text { Discipline } \\ \text { Collaboration }\end{array} & \text { to } & \text { Social Industry World } \\ \text { From } & \text { Product } & \text { to } & \text { Business Modeling } \\ \text { From } & \begin{array}{c}\text { Document } \\ \text { Management }\end{array} & \text { to } & \text { Experience Management } \\ \text { From } & \text { Search } & \text { to } & \text { Dashboard Intelligence } \\ \text { From } & \text { Productattributes } & \text { to } & \text { Consumer Experience }\end{array}$

Fig. 4. PLM Innovation

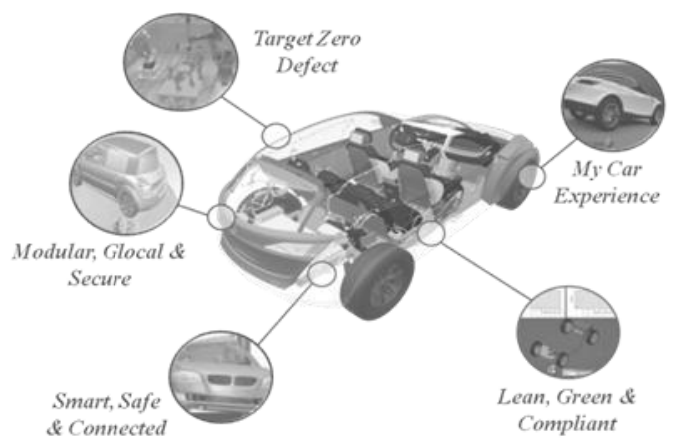

Fig. 5. Transportation and Mobility Industry Solution Experience 


\subsubsection{My Car Experience}

The purpose of this experience is to understand how the customers are expecting the next generation of the mobility services by providing some innovative ways to collect their needs and identify the market trends, to enable crowd-sourcing and co-creation around new concepts and social innovative design. Powerful 3D design tools to boost the industrial innovation process and efficient tools to perform virtual car clinics and showroom, with augmented reality and immersive reality, will be introduced. A virtual in-car feeling by enabling new in-car experience, including driving experience will lead to new design and engineering front loading experience, thus reducing the time to market and reducing physical prototypes.

\subsubsection{Lean, Green and Compliant}

The purpose of this experience is to improve vehicle energy efficiency upfront with light weight and green propulsion and to explore new ways of progress by optimizing the energy balance and the weight. Providing an end-to-end solution for EV and HEV propulsion concepts development accompany companies in their will to be more environmentally responsible. An integrated platform for vehicle validation and certification to define, manage and monitor the validation and verification process (physical and virtual test) insures requirements validation. The compliance towards global regulations and certifications (material compliance, FMVSS, CAVA, passive safety, etc.) help to optimize the vehicle performance globally and by providing a multi-physics simulation platform to evaluate and optimize all the performance of the vehicle, increased product quality and satisfying sustainability results can be harvested.

\subsubsection{Smart, Safe and Connected}

The market today is challenged by a re-invention of the mobility experience as $80 \%$ of vehicle innovations are coming from embedded systems and development moves from vehicle attributes to vehicle experience. A huge complexity in the number of ECUs, lines of code of software and an increasing number of functional requirements makes car design error prone, resulting in 20 to $40 \%$ of vehicle development cost spent in testing and diagnostics. The market demands to improve quality and safety and decreasing the number of warranty cost and cars recalls. To demonstrate functional safety against class actions lawsuits and to standardize on industry initiatives such as Software re-use (AUTOSAR), Strengthen safety (ISO26262) and early validation are mandatory to support next generation car developments. The concept of Functional Mock up that integrates mechanical, electronics, software and simulation, is key to design and simulate the car of the Future: smarter, safer and always connected.

\subsubsection{Modular, Glocal ${ }^{2}$ and Secure}

This experience allows defining the technical requirements from a marketing analysis and ideation process done on unstructured data, to define the vehicle portfolio and

\footnotetext{
${ }^{2}$ Glocal $=$ Global and local
} 
monitor the program: project dashboards, program $360^{\circ}$ and quality plans (incl. suppliers). Platforms and modules, interfaces as well as the vehicle architecture (volumes, technological choices, etc.) are managed along the defined configurations. The management of the EBOM is based on a modular approach and support the Digital Mock-up review processes (Design, Manufacturing and Simulation) in a distributed environment (Suppliers, R\&D centers,). The MBOM manages the assembly processes per manufacturing plant and the supply chain, from engineering to after sales, including sourcing, RFQ/Supplier choice process, and the contract and cost management, etc. are integrated as well.

\subsubsection{Target Zero Defect}

To ensure a zero defect process End-to-End on all the domains, extend the zero geometry defect to the End-to-End, and taking full benefit of new system engineering and collaboration environments is the purpose of this experience.

Capitalizing and reusing knowledge globally for design, manufacturing and simulation will promote innovative tools and methodologies in Architecture and Conceptual phases of the processes. Augmented simulation contribution and key differentiators in all steps of the processes will improve productivity and efficiency to reduce cycles by providing Best-of-Class solutions.

\section{Conclusions}

With the 3DEXPERIENCE platform companies create "social enterprises" that involve their customers in the innovation process. With its online architecture the 3DEXPERIENCE environment enables businesses to test and evaluate - anywhere in the development lifecycle of a product or service - the eventual experience they will deliver to their customers.

\section{References}

1. Charles, B., Menghini, M.: 3DS Corporate Strategy presentation 2012

2. 3DS 3DExperience Universe for Sustainable Innovation, http : / www . 3 ds . com/ company/about-dassault-systemes/our-vision/

3. Sappin, O., Belloncle, G.: 3DS Transportation and Mobility Industry Referential presentation (2012)

4. 3DS Transportation and Mobility 3DExperience Platform, http: / /www. 3ds.com/ solutions/transportation-mobility/overview/

5. Transportation and Mobility Smart, Safe and Connected Solution Experience, http://www.3ds.com/solutions/transportation-mobility/ industry-experiences/smart-safe-and-connected/

6. 3DS Annual Report 2012 